\title{
Thermogenesis above maintenance in humans
}

\author{
BY N. G. NORGAN \\ Department of Human Sciences, Loughborough University, Loughborough LE11 $3 T U$
}

The responses to overfeeding in humans have been the subject of considerable interest and controversy. About 20 years ago Miller et al. (1967) revitalized the idea of an energy-dissipating mechanism operating during overfeeding to maintain energy homeostasis. The effect had been proposed by Neumann (1902) at the turn of the century to explain an apparent ability to maintain his weight on widely different energy intakes. Miller et al. (1967) suggested this occurred after meals and was potentiated by work. Such a mechanism would have implications in understanding the origins of obesity and the question of adaptations to varying planes of nutrition, undernutrition as well as overnutrition. At that time (1967), measurements of individual $24 \mathrm{~h}$ energy expenditure were of unknown accuracy. Developments in instrumentation and the construction of calorimeter rooms marked a new period of more precise measurements and the application of more accurate techniques in general. From this has come evidence of differing responses to overfeeding in humans and small rodents, such that there is doubt as to the relevance of mechanisms of facultative regulatory thermogenesis in small mammals (Rothwell \& Stock, 1979) to humans. Facultative thermogenesis in response to overfeeding results from no net synthesis or mechanical work being performed. It has the effect of reducing the efficiency of energy utilization ( $\mathrm{kJ}$ gain/excess $\mathrm{kJ}$ ) and so regulating the energy stores in the body. Obligatory thermogenesis in respect to overfeeding results from the thermic effect of the extra food, its ingestion, digestion, absorption and processing. In the present paper, an overview is presented of recent studies of human overfeeding and the mechanisms behind the responses.

\section{MAINTENANCE}

Maintenance, in the context of nutritional energetics, refers to constant body energy content over a period of at least $24 \mathrm{~h}$. It is also used as a shorthand notation for maintenance energy intake or requirement, the energy intake required for constant body energy content. It is a term that appears widely in the animal and comparative nutrition literature and is used in a consistent manner, being a landmark in the continuum, minimal, basal, fasting, maintenance, habitual, up to maximal energy expenditure. Like many of these landmarks, it depends on the conditions of the measurement. The major determinants of maintenance are: (1) the body size and composition, (2) the degree of physical activity, (3) the thermic effects of feeding, (4) thermoregulatory heat production, (5) the genotype. In animals, physical activity and thermoregulatory heat production are usually kept to a minimum during the measurement of maintenance. The interspecies mean is about $440 \mathrm{~kJ} / \mathrm{kg}$ live weight $(\mathrm{W})^{0.75}$ per d compared to the basal metabolism of $290 \mathrm{~kJ} / \mathrm{kg} \mathrm{W}^{0.75}$ per $\mathrm{d}$ so that, as a rule of thumb, the energy cost of maintenance has been taken as 1.5 times basal metabolic rate (BMR).

Constant body energy content can be achieved on a range of energy intakes with consequent effects on body size, energy stores and physical activity. In human nutrition 
maintenance is an uncommon term, and is used inconsistently to refer to both the minimum level compatible with survival and habitual energy intakes. In overfeeding studies, maintenance may refer to the initial levels of the subjects in a metabolic unit or continuing with their everyday lives. Estimates of maintenance requirements of men and women from calorimeter studies agree well with the animal values, 432 (SD 33) kJ/kg $W^{0.75}$ per d (Van Es et al. 1984). Dauncey (1981) reported lower values, 373 (SD 20) $\mathrm{kJ} / \mathrm{kg} \mathrm{W} \mathrm{W}^{0.75}$ per $\mathrm{d}$, the difference probably being a result of the higher calorimeter temperature, 28 and $21^{\circ}$ and shorter exercise periods, 30 and $75 \mathrm{~min} / \mathrm{d}$ respectively. The maintenance requirement of many individuals in today's sedentary society may fall below 1.5 times BMR and even 1.4 times BMR (Prentice et al. 1985) at least in the short term. It is not known if these can be regarded as compatible with long-term good health. Maintenance is clearly a function of the conditions of the measurement. The responses to energy intakes above maintenance will depend on these conditions and the pre-existing maintenance state, the energy stores and the genotype.

\section{RESPONSES TO SUPRA-MAINTENANCE ENERGY INTAKES}

Supra-maintenance intakes (overfeeding) bring about increases in body-weight and energy stores and rises in $24 \mathrm{~h}$ energy expenditure and its components, basal and resting metabolism and the thermic effect of food. The magnitude of the responses depends on: (1) the level and duration of overfeeding, (2) the source of energy; fat, carbohydrate or mixed, (3) the fate of the excess energy, whether stored as triglyceride or glycogen, (4) the current maintenance level, (5) the genotype. The responses are adaptive in that they may allow the attainment of a new state of maintenance after several months or years but at a higher level of energy stores.

Weight gain is not a thermic response but it influences $24 \mathrm{~h}$ energy expenditure. The composition of the static difference between lean and obese individuals is $25 \%$ fat-free mass (FFM) and 75\% fat (FM) (Webster et al. 1984). However, Forbes et al. (1986) found a higher FFM component, $40-45 \%$ depending on the method of calculation, in the weight gained by overfeeding. Weight gain and lean body mass (LBM) gain were significantly correlated with excess energy intakes in forty-eight individuals $(r 0.77$ and 0.49 respectively, $P<0.01$ ). They were linearly related, with intercept terms near zero, suggesting no evidence for varying efficiency of utilization in response to overfeeding over the range 80-300 $\mathrm{MJ}$. This could not be expected to persist indefinitely as the increasing weight would decrease the energy available for gain. There was, however, considerable inter-individual differences in the responses to a given excess energy intake.

Forbes (1987) has also shown how the composition of weight gain in overfeeding is affected by the initial level of energy stores, that is the current maintenance state. Individuals with $10 \mathrm{~kg}$ body fat gain weight of $50 \% \mathrm{LBM}$, on average, those with $30 \mathrm{~kg}$, gain weight with $25 \%$ LBM on average. As the energy cost of gain $(\mathrm{kJ} / \mathrm{g})$ depends on the composition of the gain, the efficiency of energy utilization ( $\mathrm{kJ}$ stored/excess $\mathrm{kJ}$ ) may vary in individuals with different body compositions. This illustrates how different responses may occur at different maintenance states but it does not represent regulatory thermogenesis.

The thermic responses to overfeeding mixed diets in six studies arranged in order of increasing duration are shown in Table 1. The results indicate that $24 \mathrm{~h}$ energy expenditure and resting metabolic rate (RMR), measured $12-14 \mathrm{~h}$ after the last meal, are 
Table 1. Thermic responses to overfeeding mixed diets

(Mean values with their standard errors)

\begin{tabular}{|c|c|c|c|c|c|c|c|c|c|}
\hline \multirow[b]{2}{*}{ Study } & \multirow[b]{2}{*}{ Duration (d) } & \multirow[b]{2}{*}{$n$} & \multirow[b]{2}{*}{ Sex } & \multicolumn{2}{|c|}{$\begin{array}{l}24 \mathrm{~h} \text { energy } \\
\text { expenditure } \\
(\% \text { increase) }\end{array}$} & \multicolumn{2}{|c|}{$\begin{array}{c}\text { Resting } \\
\text { metabolism } \\
\text { (\% increase) }\end{array}$} & \multicolumn{2}{|c|}{$\begin{array}{c}\text { Excess } \\
\text { energy } \\
\text { (\% expended) }\end{array}$} \\
\hline & & & & Mean & SE & Mean & SE & Mean & SE \\
\hline Dauncey (1980) & 1 & 8 & o, $q$ & $10^{* * *}$ & 2 & $12^{* * *}$ & 3 & 13 & 3 \\
\hline Ravussin et al. (1985) $\dagger$ & 9 & 5 & 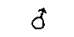 & $15^{*}$ & - & $8^{*}$ & $(0-18) \ddagger$ & - & - \\
\hline Apfelbaum et al. (1971) & 15 & 8 & q & 11 & - & $13^{* *}$ & - & 15 & - \\
\hline Wclle et al. (1986) & 20 & 5 & $\delta, \hat{\gamma}$ & - & - & 7 & $(1-18) \ddagger$ & - & - \\
\hline Forbes et al. (1986) & 21 & 15 & 5,9 & - & - & 9 & 2 & - & - \\
\hline Norgan \& Durnin (1980) & 42 & 6 & $\delta$ & 11 & - & 12 & 3 & 15 & - \\
\hline
\end{tabular}

$\dagger$ Increases are for day 9 of overfeeding.

$\ddagger$ Range.

Mean percentage increase was significant: ${ }^{*} P<0.05,{ }^{* *} P<0.01,{ }^{* * *} P<0.001$.

Table 2. Thermic responses to overfeeding high-fat and high-carbohydrate diets

\begin{tabular}{|c|c|c|c|c|c|c|c|c|c|}
\hline \multirow[b]{2}{*}{ Study } & \multirow[b]{2}{*}{ Duration (d) } & \multirow[b]{2}{*}{$n$} & \multirow[b]{2}{*}{ Sex } & \multicolumn{2}{|c|}{$\begin{array}{l}24 \mathrm{~h} \text { energy } \\
\text { expenditure } \\
\text { (\% increase) }\end{array}$} & \multicolumn{2}{|c|}{$\begin{array}{c}\text { Resting } \\
\text { metabolism } \\
\text { (\% increase) }\end{array}$} & \multicolumn{2}{|c|}{$\begin{array}{c}\text { Excess } \\
\text { energy } \\
(\% \text { expended })\end{array}$} \\
\hline & & & & Mean & SE & Mean & $\mathrm{SE}$ & Mean & $\mathrm{SE}$ \\
\hline \multicolumn{10}{|l|}{ High-fat diet } \\
\hline Dallosso \& James (1984a) & 7 & 8 & $\delta$ & $6^{* *}$ & $(2-10)^{\dagger}$ & $4^{* * *}$ & - & 10 & $(4-18)^{\dagger}$ \\
\hline Zed \& James (1986) & 6 & 8 & 9 & 8 & 1 & 10 & 2 & 14 & 1 \\
\hline \multicolumn{10}{|l|}{ High-carbohydrate diet } \\
\hline Schutz et al. (1985) & 7 & 3 & 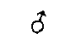 & $(12,40) \ddagger$ & - & - & - & 27 & - \\
\hline Bisdee \& James (1984) & 14 & 8 & $\delta$ & 10 & 1 & 10 & 2 & 18 & 1 \\
\hline
\end{tabular}

$\dagger$ Range.

$\ddagger$ Averages on day 1 and day 7 of overfeeding.

Mean percentage increase was significant: ** $P<0.01$, *** $P<0.001$.

raised by some $7-15 \%$. The effect begins within $24 \mathrm{~h}$ but appears unaffected by the duration or amount of overfeeding. This is true too for the proportion of the excess energy expended by this stimulated metabolism.

The responses to high fat or carbohydrate overfeeding are shown in Table 2 . With high-fat supplements, rises in metabolic rate are smaller and less is expended. For a given excess, energy gains are higher for fat overfeeding than with mixed diets. With high-carbohydrate diets, increases in $24 \mathrm{~h}$ energy expenditure up to $40 \%$ were measured by Schutz et al. (1985). Here, increasing amounts of a very-high-carbohydrate supplement, predominantly sucrose, were fed and weight was gained at $0.7 \mathrm{~kg} / \mathrm{d}$. Over the whole of the overfeeding period, the average excess energy intake was $7.5 \mathrm{MJ} / \mathrm{d}$ and the raised metabolism was equivalent to $27 \%$ of the excess. The responses in the study of Bisdee \& James (1984) with intakes of 1.5 times maintenance from supplements of starch and sucrose are more comparable to those with mixed diets. 
Sims (1986) has summarized the results of all recent studies of overfeeding. What these typical studies show is that increases in metabolic rate are of the order of $5-15 \%$ depending on the type of overfeeding and occur rapidly, within $1 \mathrm{~d}$. The percentage of the excess energy intakes expended in this stimulated metabolism is about $10-15$. The most notable feature in the responses is the variability within each study. Its origins are difficult to identify. There are few measurements of repeated overfeeding and it is not known how real the differences are. However, over half the studies have values from calorimeters which have a high precision and reliability. Forbes et al. (1986) could find no effect of initial body-weight, fat content, sex, duration of overfeeding, type of food, maintenance intake or smoking behaviour on g gain/excess energy. Type II errors, accepting the null hypothesis when it is false, are a danger in all these overfeeding studies with their small sample sizes. Earlier, Dallosso \& James (1984a) found that in men the proportions of the excess energy expended was inversely related to initial fatness. This may be related to the higher proportion of fat in the gain of fatter individuals described previously. Genotype may also have an effect. Bouchard (1987) has described the role of genetic factors in body composition and energy metabolism. Estimates of heritability based on intra-class correlation suggest significant effects on body composition, energy intake, physical activity, energy expenditure and adipose tissue metabolism. In a study of six monozygotic twins overfed $22 \mathrm{~d}$, resting metabolic rates increased $7 \%$ with considerable, but non-significant, within-pair resemblance $(r 0 \cdot 43, F=2 \cdot 51$, not significant). The magnitude of the change in the thermic effect of a meal showed significant within-pair resemblances $(r 0.70, F=5 \cdot 5, P<0.05$; Poehlman et al. 1986).

The rises in metabolism and consequent losses of excess energy result from the increased body size, the thermic effect of the extra food, including the costs of net storage, and any facultative, regulatory thermogenesis. The latter component cannot be measured directly and is usually demonstrated by rises in metabolism unexplained by the other two factors, or by pharmacological intervention. The increases in metabolic rate exceed those of body-weight except in the $42 \mathrm{~d}$ study of Norgan \& Durnin (1980) and the time-course of the responses suggest that weight gain is not the major effector. However, the thermic effect of the extra food is related to the degree of overfeeding of mixed diets (Ravussin et al. 1985; Welle et al. 1986).

The expected rise depends on the costs of storage and the composition of the gain. The theoretical costs (Flatt, 1978) for fat deposition are 3\% of the excess when fat is the substrate and $23 \%$ with carbohydrate. For glycogen deposition it is $7 \%$ and protein $25 \%$. The true costs are difficult to measure and it cannot be stated categorically that what is being measured does not have a regulatory component but in growing, simple-stomached animals they are about $25 \%$ of the excess for fat and $55 \%$ for protein deposition (Webster, 1988). In humans, with their limited capacity for lipogenesis from carbohydrate, the cost of fat deposition may be lower. Recent values from low-birth-weight infants are 15 and $42 \%$ (Roberts \& Young, 1988). For weight gain of $40 \%$ LBM and $60 \%$ fat described by Forbes et al. (1986), it would be expected that $20 \%$ of the excess would be expended in storage. Most of the losses in Tables 1 and 2 are below this value so that, even without taking into account the effect of higher body-weight on energy expenditure, there may be no need to invoke a facultative, regulatory, component. However, the estimates are tenuous and other evidence, including responses to single carbohydrate loads, have been interpreted as evidence of facultative thermogenesis. 
FACULTATIVE REGULATORY THERMOGENESIS IN HUMANS

Several mechanisms for facultative regulatory thermogenesis have been proposed including uncoupled oxidative phosphorylation, and increases in protein turnover, sodium pumping and futile cycling, under the actions of the sympathetic nervous system (SNS), catecholamines, the thyroid hormones and insulin. There has been considerable support in recent years for uncoupling in brown adipose tissue (BAT) mediated by the SNS and catecholamines, at least in small animals. This follows the suggestion of Rothwell \& Stock (1979) that cold and diet had similar effects on metabolism and on BAT in particular. Although evidence is accumulating of the presence of BAT in adults and of the $32 \mathrm{~K}$ uncoupling protein, the contribution to noradrenaline stimulated thermogenesis appears low (Cunningham et al. 1985). The importance of BAT and the evidence for SNS stimulation of BAT or thermogenesis in other organs in response to overfeeding in humans is unresolved (Sims, 1986). Ingestion of protein, fat and carbohydrate at maintenance results in significant thermic responses, but raised plasma noradrenaline concentration is observed only after carbohydrate (Welle et al. 1981), and Astrup et al. (1985) have proposed skeletal muscle as the site of a facultative component of glucose-induced thermogenesis.

With overfeeding mixed diets, neither Ravussin et al. (1985) nor Welle et al. (1986) found support for the involvement of the SNS or thyroid hormones. Responsiveness to infused noradrenaline was not enhanced and $\beta$-blockade with propranolol had the same effect before and after overfeeding. SNS involvement in the greater rises in $24 \mathrm{~h}$ energy expenditure with carbohydrate overfeeding was found by Schutz et al. (1985) but not by Welle \& Campbell (1983). Using the euglycaemic glucose clamp procedure, Acheson et al. (1983) found that the later part of the thermic effect of glucose was $\beta$-blockable, i.e. an SNS-mediated facultative component. However, these are acute unphysiological conditions.

Plasma levels of the thyroid hormone triiodothyronine $\left(\mathrm{T}_{3}\right)$ are altered by energy balance in the same direction as metabolic rate. Increases with overfeeding are found with carbohydrate and mixed-diet overfeeding but not with fat. Induced mild $\mathrm{T}_{3}$ toxicosis raised RMR by $6 \%$ but had no effect on the thermic effect of food or the efficiency of exercise (Acheson et al. 1984). The roles of the thyroid hormones and the sodium pump in thermogenesis are described in the preceding papers of Dauncey (1990) and Kelly \& McBride (1990). These and other possible mechanisms have been reviewed by Sims (1986).

The original proposal for facultative thermogenesis in overfeeding was a workpotentiated increase (Miller et al. 1967). Garrow (1978) found little evidence for this effect in his review of the literature and this has been confirmed by Dallosso \& James (1984b), Welle (1984), and Welle et al. (1986). Segal \& Gutin (1983) reported a potentiation in women but the effects during work were small $(50 \mathrm{~kJ})$. In men, the potentiation was $60 \mathrm{~kJ} / 3 \mathrm{~h}$ (Segal et al. 1987). In the overfeeding twin study of Bouchard and colleagues (Tremblay et al. 1987), no significant increase in mean exercise oxygen consumption was observed with overfeeding but there was again a large variation and moderate to high within-pair resemblances in responses $(r 0 \cdot 51-0 \cdot 78, F=3 \cdot 0-8 \cdot 2, P$ not significant $-<0 \cdot 05)$, i.e. a genotype-overfeeding interaction. High but non-significant intra-class correlation coefficients $(0 \cdot 4-0.7)$ between changes in exercise $\mathrm{O}_{2}$ consumption with overfeeding and plasma catecholamines and, negatively, body-fat gain were described as consistent with the concept of a role for the sympathoadrenal system in the regulation of adaptive thermogenesis and the predisposition to store fat. 


\section{THERMOGENESIS BELOW AND AT MAINTENANCE}

If a facultative regulatory mechanism is effective, it may be evident below and at maintenance and there are many observations that have been interpreted in this way. Seventy years ago, Benedict et al. (1919) showed that metabolic rate fell faster than weight in experimental undernutrition and recovered faster too. The magnitude of the effect was related to the increase with overfeeding, $10 \%$, which suggested a common or similar mechanism, but being suppressed instead of activated. More recently, Jung et al. (1979) reported a difference in the thermic response to noradrenaline in the obese and the previously obese compared with controls. Although the evidence in man is equivocal, it has been interpreted as consistent with a suppression of sympathetic activity with energy restriction (Landsberg \& Young, 1983). However, Mansell \& MacDonald (1988) underfed six women for $7 \mathrm{~d}$ and found similar changes in metabolic rate and plasma noradrenaline following a test meal in the maintenance and underfed states, suggesting no SNS suppression. Similarly, intravenous infusion of nutrients produced effects unaltered by $\beta$-adrenergic blockade (Vernet et al. 1987).

What of the chronic energy deficiency of the Third World? Gambian women show a remarkable adaptation in the first two trimesters of pregnancy of reducing their BMR. However, similar decreases have been reported in some women in this country (Prentice et al. 1989). In both countries, the change in BMR is positively related to initial fatness, i.e. the pre-existing maintenance condition. Similar effects might be expected in lactating women, lactation being equally energy demanding, but there is no evidence for falls in BMR. The thermic effect of food and responses to noradrenaline are lower and insulin sensitivity is increased (Illingworth et al. 1987). The effect is equivalent to $200 \mathrm{~kJ} / \mathrm{d}$. In rodents, the mechanism appears to be reduced BAT thermogenesis.

Further examples of the responses to food and overfeeding varying with maintenance state are the negative relationships between fatness and thermic effect of food (Robson et al. 1977), work-potentiated thermic effect of food (Segal et al. 1984) and the proportion of the excess energy expended (Dallosso \& James, 1984a).

The question of small and large eaters on apparently similar activity patterns has been raised many times over the last 50 years. Do the big eaters exhibit regulatory thermogenesis? Apparently not. The big eaters are invariably heavier than the small eaters. When matched for size as in the recent study of McNeill et al. (1988a) there were no significant differences in $24 \mathrm{~h}$ energy expenditure and BMR measured under controlled conditions. This casts doubt on the representativeness of the intake values, particularly when these are barely sufficient to meet requirements for BMR. Related to this is the suggestion that maintenance requirements are raised in the obese, particularly the experimentally obese, and reduced in the post-obese who have maintained weight for several months. In the Vermont prison studies, it was reported that maintenance requirements of the overfed had increased $50 \%$ even though weight gain was only $25 \%$. However, energy expenditure was not measured and, again, there are doubts about the intake values. In the obese, increases in $24 \mathrm{~h}$ energy expenditure are explained largely by increased FFM (Ravussin et al. 1981) and interest has been in thermogenic defects, such as a blunted response to food, an effect that could contribute to weight gain. One suggestion is that this blunted response is related to insulin resistance and impaired glucose tolerance and reduced rates of glucose disposal and storage. When glucose uptake is held constant by varying insulin infusion, the effect of glucose is the same in lean and obese subjects (Ravussin et al. 1983). 
In the post-obese, there is no consistency in the findings. Basal or resting metabolism has been reported as being normal (McNeil et al. 1990), lowered (Geissler et al. 1987) and raised (Tremblay et al. 1989). The thermic effect of food too has been reported recently as being unchanged compared with controls. There is less information on $24 \mathrm{~h}$ energy expenditure and the possibility of reduced activity but there is no evidence that the post-obese of average size can live on low energy intakes. Suggestions that those who regularly lose then regain weight, weight cyclers or yoyo dieters, may have energetic abnormalities has not yet been substantiated. In animals, increased efficiency ( $g$ gained/excess $\mathrm{kJ}$ ) has been reported. One mechanism might be a reduced RMR but this was not observed by Van Dale \& Saris (1989) or Goldberg et al. (1990), as reported at the present meeting. The latter study of seven women with $6 \%$ weight loss in three 2-week cycles found no decreases in absolute BMR or per kg FFM and no excessive loss of lean tissue.

Energy intake is intermittent. Short- or long-term storage is required along with a mechanism to partition nutrients between metabolism and storage, and mobilization of stores. If there were a propensity to use more or less efficient pathways this could have implications for weight gain. However, fuel mixtures over $24 \mathrm{~h}$ are closely related to diet composition (Hurni et al. 1982) and fasting respiratory quotient is unrelated to body composition (McNeil et al. 1988b).

\section{CONCLUSIONS}

There is little evidence for significant facultative regulatory increases in energy expenditure with supra-maintenance intakes in normal weight adults, certainly not sufficient to dispose of intakes of 1.5 times maintenance. Large obligatory increases occur with high-carbohydrate loads and there may be a facultative component. These are rather unphysiological conditions and extrapolation to other conditions may be unjustified. Involvement of the sympathetic nervous system is controversial and the maximum stimulation of resting energy expenditure for any period of time by pharmacological doses of noradrenaline may only be about $20 \%$. However, a 1 or $0.1 \%$ rise in efficiency might be enough to lead to obesity, in the absence of compensatory changes in energy intake. In considering the origins of obesity, Jequier \& Schutz (1985) have calculated that if there exists a defect in the thermogenic response to food of about one-third, by the time $10 \mathrm{~kg}$ weight had been gained, the raised energy expenditure from the increased weight would balance the energy saving. Therefore, in obesity, defective thermogenesis alone is unlikely to be the only cause and defective appetite control may be implicated, too.

Facultative thermogenesis in overfeeding diets of mixed energy sources appears a rather elusive phenomenon. Stock \& Rothwell (1987) have said in relation to the animal work that an elusive phenomenon may still be an important one and that, if in the past, elusive phenomena in science had been ignored, our knowledge and understanding would be much less than it is today. The individual variability in the responses to overfeeding requires more detailed study. 


\section{REFERENCES}

Acheson, K., Jequier, E., Burger, A. \& Danforth, E. Jr (1984). Thyroid hormones and thermogenesis: the metabolic cost of food and exercise. Metabolism 33, 262-265.

Acheson, K., Jequier, E. \& Wahren, J. (1983). Influence of $\beta$-adrenergic blockade on glucose-induced thermogenesis in man. Journal of Clinical Investigation 72, 981-986.

Apfelbaum, M., Bostarron. J. \& Lacatis, D. (1971). Effect of caloric restriction and excessive caloric intake on energy expenditure. American Journal of Clinical Nutrition 24, 1405-1409.

Astrup, A., Bulow, J.. Madsen. J. \& Christensen, J. (1985). Contribution of BAT and skcletal muscle to thermogenesis induced by ephedrine in man. American Journal of Physiology 248, E507-E515.

Benedict, F. G.. Miles, W. R., Roth, P. \& Smith, M. (1919). Human Vitality and Efficiency under Prolonged Restricted Diet. Washington, DC: Carnegie Institution of Washington.

Bisdee, J. T. \& James, W. P. T. (1984). Carbohydrate-induced thermogenesis in man. Proceedings of the Nutrition Society 43, 149A.

Bouchard, C. (1987). Genetics of body fat, energy expenditure and adipose tissue metabolism. In Recent Advances in Obesity Research V, pp. 16-25 [E. M. Berry, S. H. Blondheim. H. E. Eliahou and E. Shapiro, editors]. London: John Libbey and Co Ltd.

Cunningham, S., Leslie, P., Hopwood, D., Illingworth, P.. Jung, R. T., Nicholls, D. G.. Peden, N., Rafael. J. \& Rial. E. (1985). The characterization and energetic potential of brown adipose tissue in man. Clinical Science 69, 343-348.

Dallosso. H. M. \& James, W. P. T. (1984a). Whole body calorimetry studies in adult man. 1. The effect of fat-overfeeding on 24 h energy expenditure. British Journal of Nutrition 52, 49-64.

Dallosso, H. M. \& James, W. P. T. (1984b). Whole body calorimetry studies in adult man. 2 . The interaction of exercise and overfeeding on the thermic effect of a meal. British Journal of Nutrition 52, 65-72.

Dauncey, M. J. (1980). Metabolic effects of altering the $24 \mathrm{~h}$ energy intake in man, using direct and indirect calorimetry. British Journal of Nutrition 43, 257-269.

Dauncey, M. J. (1981). Influence of mild cold on $24 \mathrm{~h}$ energy expenditure, resting metabolism and diet-induced thermogenesis. British Journal of Nutrition 45, 257-267.

Dauncey. M. J. (1990). Thyroid hormones and thermogenesis. Proceedings of the Nutrition Society 49, 203-215.

Flatt, J. P. (1978). The biochemistry of energy expenditure. In Recent Advances in Obesity Research 2. pp. 211-228 [G. A. Bray, editor]. London: Newman Publishing.

Forbes, G. B. (1987). Lean body mass - body fat interrelationships in humans. Nutrition Reviews 45, 225-231.

Forbes, G. B., Brown, M. R., Welle, S. L. \& Lipinski, B. A. (1986). Deliberate overfeeding in women and men: energy cost and composition of weight gain. British Journal of Nutrition 56. 1-9.

Garrow. J. S. (1978). Energy Balance and Obesity in Man. 2nd ed. Amsterdam: Elsevier.

Geissler, C. A., Miller, D. S. \& Shah, M. (1987). The daily metabolic rate of the post-obese and the lean. American Journal of Clinical Nutrition 45, 914-920.

Goldberg, G. R., Parkinson, S. A., Savage, J. M., Murgatroyd, P. R. \& Prentice, A. M. (1990). Repeated periods of dieting by women using a very low energy diet. 1. Effect on metabolic rate. Proceedings of the Nutrition Society 49, 11 A.

Hurni, M., Burnand, B., Pittet, P. H. \& Jequier, E. (1982). Metabolic effects of a mixed and a high carbohydrate low fat dict in man, measured over $24 \mathrm{~h}$ in a respiration chamber. British Journal of Nutrition 47, 33-43.

Illingworth, P. J., Jung, R. T. \& Howie, P. W. (1987). Energy balance in lactation. In Recent Advances in Obesity Kesearch V. pp. 257-265 [E. M. Berry, S. H. Blondheim, H. E. Eliahou and E. Shapiro, editors]. London: John Libbey and Co Ltd.

Jequier. E. \& Schutz, Y. (1985). New evidence for a thermogenic defect in human obesity. International Journal of Obesity 9, Suppl. 2, 1-7.

Jung, R. T., Shetty, P. S., James. W. P. T., Barrand, M. A. \& Callingham, B. A. (1979). Reduced thermogenesis in obesity. Nature 279, 322-323.

Kelly, J. M. \& McBride, B. W. (1990). The sodium pump and other mechanisms of thermogenesis in selected tissues. Proceedings of the Nutrition Society 49, 185-202.

Landsberg, L. \& Young, J. B. (1983). Autonomic regulation of thermogenesis. In Mammalian Thermogenesis, pp. 99-140 (L. Giradier and M. J. Stock, editors]. London: Chapman Hall.

McNeil, G., Bruce, A. C., Ralph, A. \& James, W. P. T. (1988b). Inter-individual differences in fasting nutrient oxidation and the influence of diet composition. International Journal of Obesity 12, 455-463. 
McNeil, G., Bukkens, S. G. F., Morrison, D. C. \& Smith, J. S. (1990). Energy intake and energy expenditure in post-obese women and weight-matched controls. Proceedings of the Nutrition Society 49, $14 \mathrm{~A}$.

McNeil, G., McBride, A., Smith, J. S. \& James, W. P. T. (1988a). The energy expenditure of large and small eaters. Proceedings of the Nutrition Society 47, 138A.

Mansell, P. I. \& MacDonald, I. A. (1988). The effect of underfeeding on the physiological response to food ingestion in normal weight women. British Journal of Nutrition 60, 39-48.

Miller, D. S., Mumford, P. \& Stock, M. J. (1967). Gluttony. 2. Thermogenesis in overeating man. American Journal of Clinical Nutrition 20, 1223-1229.

Neumann, R. O. (1902). Experimentelle Beitrage zur Lehre von dem taglichen Nahrungsbedarf des Meuschen unter besonderer Berucksichtigung der notwendigen Eiweissmenge. Archives Hygiene (Berlin) 45, 1-87.

Norgan. N. G. \& Durnin, J. V. G. A. (1980). The effect of 6 weeks of overfeeding on the body weight, body composition and energy metabolism of young men. American Journal of Clinical Nuirition 33, 978-988.

Poehlman, E. T., Tremblay, A., Fontaine, E., Despres, J. P., Nadeau, J. \& Bouchard, C. (1986). Genotype dependency of the thermic effect of a meal and associated hormonal changes following short-term overfeeding. Metabolism 35, 30-36.

Prentice, A. M., Coward, W. A., Davies, H. L., Murgatroyd, P. R., Black, A. E., Goldberg, G. R., Ashford, J., Sawyer, M. \& Whitehead, R. G. (1985). Unexpectedly low levels of energy expenditure in healthy women. Lancet i, 1419-1422.

Prenticc, A. M., Goldberg, G. R., Davies, H. L., Murgatroyd, P. R. \& Scott, W. (1989). Energy sparing adaptations in human pregnancy assessed by whole body calorimetry. British Journal of Nutrition 62, 5-22.

Ravussin, E., Bogardus, C., Schwarz, R. S., Robbins, D. C., Wolfe, R.. Horton, E. S., Danforth, E. Jr \& Sims, E. A. H. (1983). Thermic effect of infused glucose in man: decreased response associated with insulin resistance in obesity and non-insulin-dependent diabetes mellitus. Journal of Clinical Investigation $\mathbf{7 2}$, 893-902.

Ravussin, E., Burnand, B., Schutz, Y.\& Jequier, E. (1981). Twenty-four-hour energy expenditure and resting metabolic rate in obese, moderately obese and control subjects. American Journal of Clinical Nutrition 35, $566-573$.

Ravussin, E., Schutz, Y., Acheson, K. J., Dusmet, M., Bourquin, L. \& Jequier, E. (1985). Short-term, mixed-diet overfeeding in man: no evidence of 'luxuskonsumption'. American Journal of Physiology 249, E470-E477.

Roberts, S. B. \& Young, V. R. (1988). Energy costs of fat and protein deposition in the human infant. American Journal of Clinical Nutrition 48, 951-955.

Robson, J. R. K., Oexman, M. J., Coale. M. S. \& Bradham, G. B. (1977). Metabolic responses to food. Lancet ii, 1367.

Rothwell, M. J. \& Stock, M. J. (1979). A role for brown adipose tissue in diet-induced thermogenesis. Nature 281, 31-35.

Schutz, Y., Acheson, K. J. \& Jequier, E. (1985). Twenty-four hour encrgy expenditure and thermogenesis: response to progressive carbohydrate overfeeding in man. International Journal of Obesity 9, Suppl. 2, $111-114$

Segal, K. R. \& Gutin, B. (1983). Thermic effects of food and exercise in lean and obese women. Metabolism 32, 581-589.

Segal, K. R., Gutin, B., Albu, J. \& Xavier Pi-Janyer, F. (1987). Thermic effects of food and exercise in lean and obese men of similar lean body mass. American Journal of Physiology 252, E110-E117.

Segal, K. R., Presta, E. \& Gutin, B. (1984). Thermic effect of food during graded exercise in normal weight and obese men. American Journal of Clinical Nutrition 40, 995-1000.

Sims, E. A. H. (1986). Energy balance in human beings: the problems of plenitude. Vitamins and Hormones 43, 1-101.

Stock, M. J. \& Rothwell, N. J. (1987). Criteria and experimental evidence for Luxuskonsumption. In Recent Advances in Obesity Research V, pp. 124-130 [E. M. Berry, S. H. Blondheim, H. E. Eliahou and E. Shapiro, editors]. London: John Libbey and Co Ltd.

Tremblay, A., Poehlman, E. T., Nadeau, A., Dussault, J. \& Bouchard, C. (1987). Heredity and overfeedinginduced changes in submaximal $\dot{\mathrm{V}}_{\mathrm{O}_{2}}$. Journal of Applied Physiology 62, 539-544.

Tremblay, A., Sauve, L., Despre's, J.-P., Nadean, A., Theriault, G. \& Bouchard, C. (1989). Metabolic characteristics of post obese individuals. International Journal of Obesity 13, 357-366.

Van Dale, D. \& Saris, W. M. (1989). Repetitive weight loss and wcight regain: effects on weight reduction, resting metabolic rate, and lipolytic activity beforc and after exercise and/or diet treatment. American Journal of Clinical Nutrition 49, 409-416. 
Van Es, A. J. H., Vogt, J. E., Niessen, C. H., Veth. J., Rodenburg, L., Teeuwse, V., Dhuyvettes, J., Deurenberg, P., Hautvast, J. G. A. J. and Van Der Beek, E. (1984). Human energy metabolism below, near and above energy equilibrium. British Journal of Nutrition 52, 429-442.

Vernet, O., Naeht, C..-A., Christin. L., Schutz, Y., Danforth, E. Jr \& Jequier, E. (1987). $\beta$-adrenergic blockade and intravenous nutrient-induced thermogenesis in lean and obese women. American Journal of Physiology 253, E65-E71.

Webster, A. J. F. (1988). Comparative aspects of energy exchange. In Comparative Nutrition, pp. $37-53$ [K. Blaxter and I. MacDonald, editors]. London: John Wiley.

Webster, J. D., Hesp, R. \& Garrow, J. S. (1984). The composition of excess weight in obese women estimated by body density, total body water and total body potassium. Human Nutrition: Clinical Nutrition 38C, 299-306.

Welle, S. (1984). Metabolic response to a meal during rest and low intensity work. American Journal of Clinical Nutrition 40, 990-994.

Welle, S. \& Campbell, R. G. (1983). Lack of catecholamine-mediated thermogenesis during carbohydrate overfecding in man. Journal of Clinical Investigation 71, 916-925.

Welle, S., Lilavivat, U. \& Campbell, R. G. (1981). Thermic effect of feeding in man: increased plasma norepinephrine levels following glucose but not protein or fat consumption. Metabolism 30, 953-958.

Welle, S. L.. Seaton, T. B. \& Campbell, R. G. (1986). Some metabolic effects of overeating in man. American Journal of Clinical Nutrition 44, 718-724.

Zed, C. \& James, W. P. T. (1986). Dietary thermogenesis in obesity: fat feeding at different energy intakes. International Journal of Obesity 10, 375-390. 